\section{Intersections}

Canadian Journal of Music

Revue canadienne de musique
Intersections CANADIAN JOURAL OF MUSIC
REVUE CANADIENEE DE MUSIOUH

\title{
Interpreting Gesture as Motive: A Transformational Perspective on Replication in R. Murray Schafer's Seventh String Quartet
}

\section{Stephanie Lind}

Volume 28, numéro 2, 2008

URI : https://id.erudit.org/iderudit/029955ar

DOI : https://doi.org/10.7202/029955ar

Aller au sommaire du numéro

\section{Éditeur(s)}

Canadian University Music Society / Société de musique des universités canadiennes

ISSN

1911-0146 (imprimé)

1918-512X (numérique)

Découvrir la revue

Citer cet article

Lind, S. (2008). Interpreting Gesture as Motive: A Transformational Perspective on Replication in R. Murray Schafer's Seventh String Quartet. Intersections, 28(2), 51-71. https://doi.org/10.7202/029955ar

\section{Résumé de l'article}

Au premier coup d'oeil, les éléments du texte, de l'instrumentation, et des conditions d'interprétations semblent nier l'importance de la structure des tons du Quatuor à cordes $n^{0} 8$ de Schafer (l'oeuvre fait appel à un soprano obligé, des motifs chromatiques et vestimentaires, et des textes basés sur des textes d'une schizophrène). Par contre, on peut déceler des liens étroits entre des motifs musicaux apparemment disparates, qui se conforment à un même geste transpositionnel. Cet article emploie l'analyse de réseaux transformationnels (transformational network analysis), une approche théorique récente qui combine des éléments empruntés aux mathématiques et à la set theory, pour illustrer les similitudes entre ces motifs musicaux. Une introduction brève à l'analyse de réseaux est aussi incluse pour ceux qui ne sont pas familiers avec la terminologie transformationnelle.
Tous droits réservés (C) Canadian University Music Society / Société de musique des universités canadiennes, 2009
Ce document est protégé par la loi sur le droit d'auteur. L'utilisation des services d'Érudit (y compris la reproduction) est assujettie à sa politique d'utilisation que vous pouvez consulter en ligne.

https://apropos.erudit.org/fr/usagers/politique-dutilisation/ 


\title{
INTERPRETING GESTURE AS MOTIVE: A TRANSFORMATIONAL PERSPECTIVE ON REPLICATION IN R. MURRAY SCHAFER'S SEVENTH STRING QUARTET ${ }^{1}$
}

\author{
Stephanie Lind
}

R. Murray Schafer's Seventh String Quartet (1999) incorporates several elements not characteristic of the string quartet genre; these include an obligato soprano part, percussion, and detailed theatrics replete with colour and costume motifs associated with each performer. As explained by the Molinari Quartet, who commissioned this work after recording the previous six quartets,

The structure of the seventh quartet has the string quartet as an entity alternate with the soprano's interventions. However, when the soprano sings, the quartet finds itself obliged to act as accompanist. The many interruptions imposed by the soprano upon the quartet and her strange comments (the texts of which are taken from the diary of a schizophrenic woman) clip the wings of the strings, who reassert themselves only in the absence of the singer. (Molinari 2007)

Schafer himself states, "The fortuitous discovery of some texts by an anonymous schizophrenic woman in a mental asylum gave me the solution: the singer would come and go throughout the music as an intruder, singing texts that are simultaneously sexual, musical and absurd" (Molinari 2007). Schafer addresses the ideas and the structure of these texts by means of certain textmusic correspondences and instrumental juxtapositions, a complete discussion of which lies beyond the scope of this article.

By a process of generic fragmentation, then, the text, its instrumentation, and its performance might distract the audience from the quartet's pitch structure. But the manner in which Schafer relates seemingly disparate pitch elements throughout the work stands in direct contrast to the fragmentation presented in the text. This article will detail how certain commonalities among pitch motives suggest larger-scale unity and continuities.

In spite of a sporadic use of aleatoric elements, the quartet has a strongly motivic pitch structure based on chromatic and octatonic pitch collections. Rather than relying on traditional variation techniques, Schafer seems to develop motives by recombining what will be called here characteristic gestures,

1 A version of this paper was read at the annual meeting of the Canadian University Music Society, where it received the Proctor Prize. 
referring in this case to the transpositions that feature prominently within each motive. For example, a gesture governing melodic motion in one motive may be transformed to generate the level of transposition between two melodic lines in a second motive.

This focus on gesture rather than object is well-suited to analysis with transformational theory, a system developed primarily by David Lewin. Transformational theory is founded on the idea that musical objects relate not by distances but by how one object is transformed to generate another. For example, the notes D and F can be described as being "a minor third apart," a description that conceptualizes their relationship as a fixed measurement between two points. From a transformational perspective, however, one might instead say, "D generates F by ascending two scale-steps in C Major," or alternately, "If D is transposed up three semitones, F results." In essence, transformational theory focuses on the process through which one object is derived from another.

Before beginning an in-depth analysis of the Quartet, a few notes should be made on the terminology used in this paper. Transformational theory adapts mathematical set theory and often incorporates the language of musical set theory as well. Thus the analyses in this paper will refer to pitch classes (that is, notes that do not specify register; for example, $C$ abstractly represents middle C, $\mathrm{C}_{5}$ an octave higher, C6 two octaves higher, and so forth). The transformations - the specific process under which one object generates another-discussed here will be primarily transpositions of the form $T_{x}$, where $T_{x}$ refers to a transposition up $\mathrm{x}$ semitones. ${ }^{2}$ Interval class refers to the smallest possible interval measured in semitones between any two pitch classes. For example, the interval class between $\mathrm{E}$ and $\mathrm{C}$ is interval class 4 . A set class is an abstract way of representing a collection of pitch classes (such as a chord) by its constituent intervals; for example, SC 0167 indicates that, beginning on any given pitch class (represented by the $o$ ), the remaining pitch classes of the set occur 1,6 , and 7 semitones away in a single direction (ascending or descending). Sets are identified as dyads, trichords, tetrachords, and so forth, on the basis of the number of different pitch classes they contain. Ordered sets are indicated by angle brackets $<>$, and unordered sets by braces \{\} .3

As an introduction to the fundamentals of network analysis, figure 1 gives an example of a network along with two related structures: a node-arrow system and a graph. The example contains several pairs of circles joined by arrows; these circles are referred to as nodes, and they function as containers for the musical objects of the analysis. Where a node-arrow system connects nodes, as in figure 1a, a specific ordering to the objects is implied. ${ }^{4}$ A node that has no arrows pointing to it is called an input, a designation that implies it gener-

2 David Lewin formally defines a transformation as "a function from a family $\mathrm{S}$ into $\mathrm{S}$ itself" (Lewin 1987, 3).

3 For an introduction to the fundamentals of pitch-class set theory, see Straus (2005). The definitions given here informally summarize those given in Straus's text.

4 Formally, a node-arrow system is "an ordered pair (NODES, ARROW), where NODES is a family (i.e. set in the mathematical sense), and ARROW is a subfamily of NODES x NODES, i.e. a collection containing some ordered pairs $\left(\mathrm{N}_{1}, \mathrm{~N}_{2}\right)$ of NODES" (Lewin 1987, 193). 


\section{a) A node-arrow system}

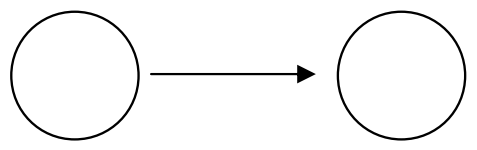

b) A graph

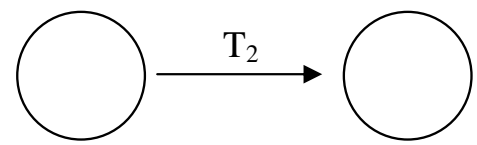

c) A network

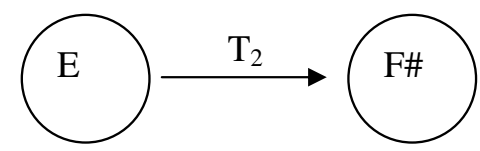

Figure 1: A network and other related structures

ates all other objects within the structure. A node with no arrows pointing away from it is called an output, a designation that implies it completes the structure. A graph, such as that given in figure $1 \mathrm{~b}$, consists of a node-arrow system in which a specific transformation is associated with each arrow. Here the transformation is a pitch-class transposition by two semitones. A network is simply a graph that has specific objects assigned to its nodes; the transformation associated with each arrow maps the content of the node at the arrow's tail to the content of the node at its head. The network in figure ic expresses the pitch class E transposed by two semitones to F\#. Identical graphs are termed isographic to one another. Since at times it will be convenient to refer to a portion of a graph or network rather than the entire structure, the terms sub-graph and sub-network will be used in certain contexts.

This analysis will concentrate upon the repetition of similar characteristic gestures. It will also demonstrate how motivic groups are formed by such repetition, groups that help both the analyst and listener to structure their hearing of the movement. To accomplish this task, two specific types of transformational networks will be used, referred to collectively as replicative networks. Such networks represent recurring motives and gestures wherein certain sub-graphs are repeated (in other words, a portion of the graph is replicated several times within the complete structure; more specific examples will be presented shortly). Having shown how the networks for each gesture share certain elemental structural features, this paper will then examine issues of continuity, unity, and closure.

Within the Quartet, the semitone is an elemental structural feature. Rather than understanding it as an interval (an object), the analyses presented herein instead interpret the semitone as a gesture (an action or transformation). In other words, the semitone expresses the transposition of a pitch or pitch class rather than the distance between two notes. In transformational terms, the semitone is commonly indicated as $\mathrm{T}_{1}$ or $\mathrm{T}_{11}$ (depending on direction) to make more explicit the action of transposition. This gesture-oriented approach is appropriate here, given that the semitone occurs not only melodically between 


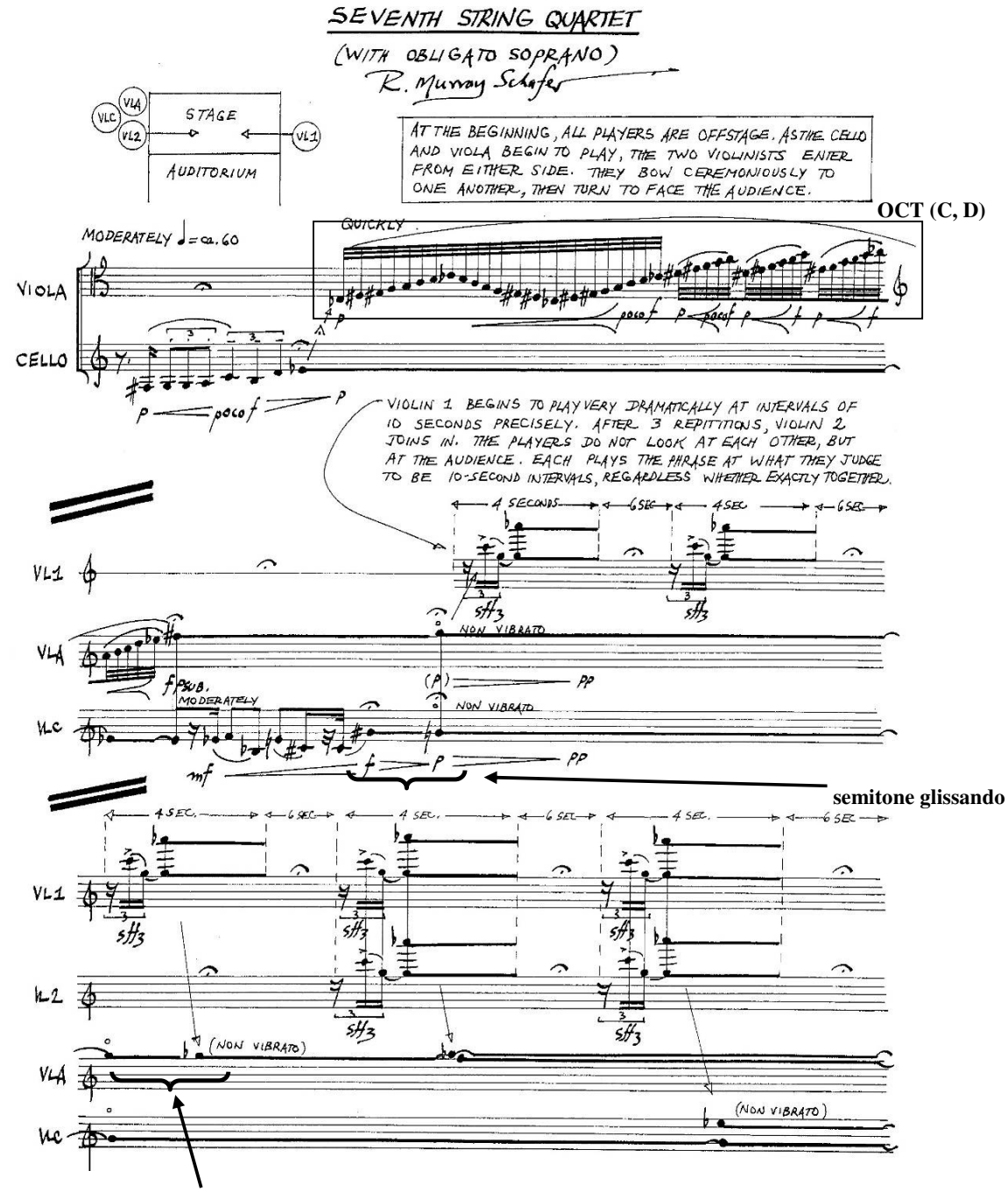

semitone glissando

(emphasized by ic1 difference

between viola and violin 1)

Figure 2: A network and other related structures

pitch classes, but also between dyads and larger sub-motives, in both the vertical (simultaneous or harmonic) and horizontal (successive or melodic) dimensions. The semitone is the characteristic transformation of the Quartet.

The opening passage, given in figure 2, introduces certain motivic elements heard throughout the quartet. First, as outlined in the figure, the viola plays a rapid gesture whose pitches belong entirely to OCT(C, D). ${ }^{5}$ Just before this

5 That is, the octatonic collection that contains the pitch classes $C$ and $D:\left\{C, D, E b, F, F^{\sharp}, G^{\sharp}, A\right.$, B $\}$. Similarly, OCT $\left(C^{\sharp}, D\right)=\left\{C^{\sharp}, D, E, F, G, A^{b}, B^{b}, B\right\}$ and $\operatorname{OCT}\left(C, D^{b}\right)=\left\{C, D^{b}, E b, E, F \#, G, A, B b\right\}$. 


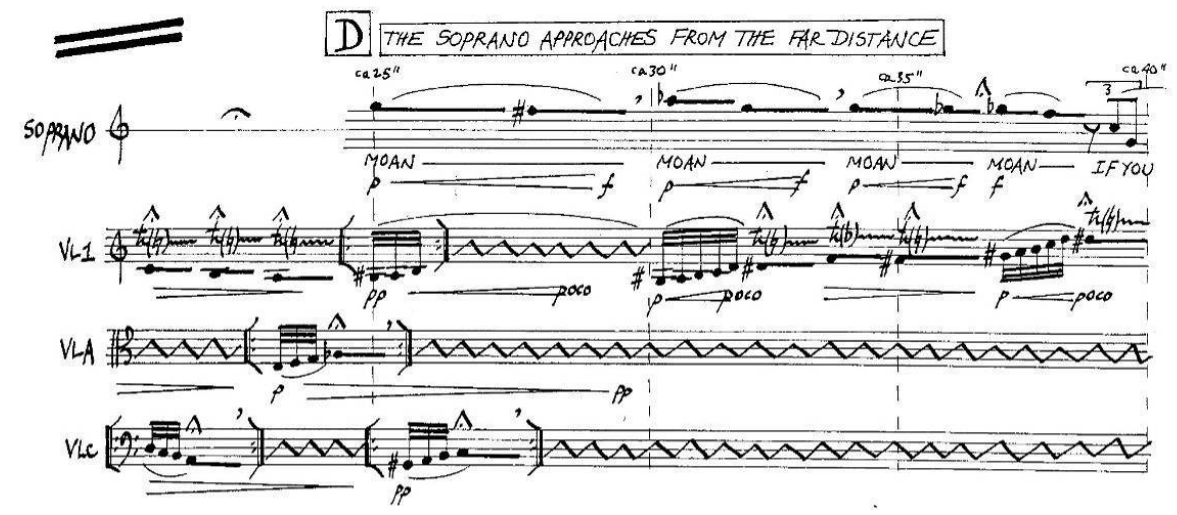

Figure 3: $\quad$ Schafer, Seventh String Quarter, page 7, last system

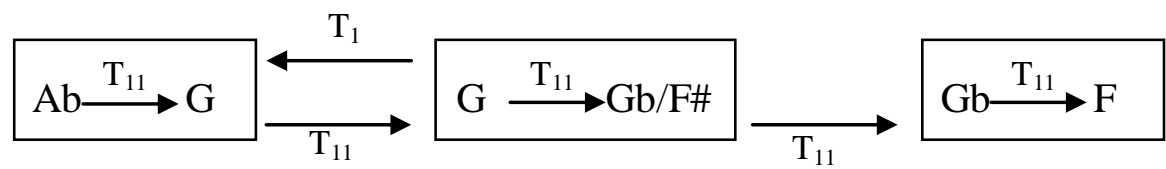

Figure 4: A transformational interpretation of the voices opening music in Schafer, Seventh String Quarter (compare fig. 3)

gesture peaks at the end of the first system, it segments into a motive that is repeated, and with each repetition it is extended by one note. The process of repetition is taken up immediately by the violins, who upon their entry in the second system repeat a motive incorporating interval classes of one, four, and five semitones. Interval class 1 , heard within this passage in the gradual descents of the viola and cello, becomes especially prominent later on.

Later, at the soprano's first entrance (see fig. 3), many of the same elements recur. As with the earlier viola motive, the repeated melodic fragments in the strings present octatonic materials, with the violin 1 and cello in $\mathrm{OCT}(\mathrm{C}, \mathrm{D})$ and the viola in OCT(C\#, D). The interval class 1 heard in the earlier passage also returns: the reiteration of the word moan in the soprano, in conjunction with breath marks, parses her line into dyads that are highly saturated with $\mathrm{T}_{11}$. Figure 4 , which analyzes the music of figure 3 transformationally, proposes a gestural similarity at multiple structural levels. Specifically, the soprano's opening gesture begins at the central node of the figure, $\mathrm{G}$, and is transformed by $\mathrm{T}_{11}$ into $\mathrm{F}$; this dyad is subsequently transformed by $\mathrm{T}_{1}$ (to the left on the network) to form $<\mathrm{A} b, \mathrm{G}>$. The soprano returns to the initial dyad by $\mathrm{T}_{11}$, and then continues via one final move of $T_{11}$ to the dyad $\langle G b, F\rangle$. This passage thus establishes $\mathrm{T}_{11}$ and its inverse, $\mathrm{T}_{1}$, as characteristic transformations both of pitch classes and dyads.

Figure 5a depicts the basic $\mathrm{T}_{11}$ transformational gesture as a two-node graph, while parts b, c, and d of the figure incorporate part a into three more complex structures: a graph-of-graphs, a sequential graph, and a product graph, respectively. Each says something different about this musical passage. In the graph- 
a) The simplest form: one structural level

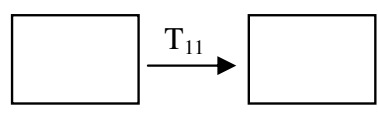

b) At two structural levels (a recursive or self-replicative network-of-networks)

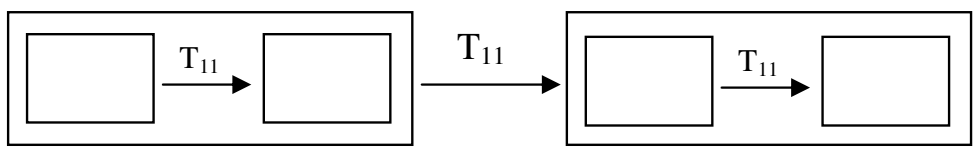

c) A sequential graph

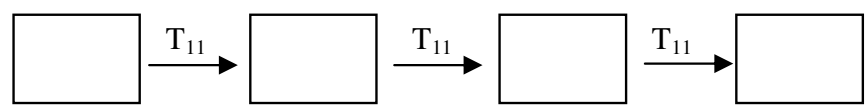

d) A product graph

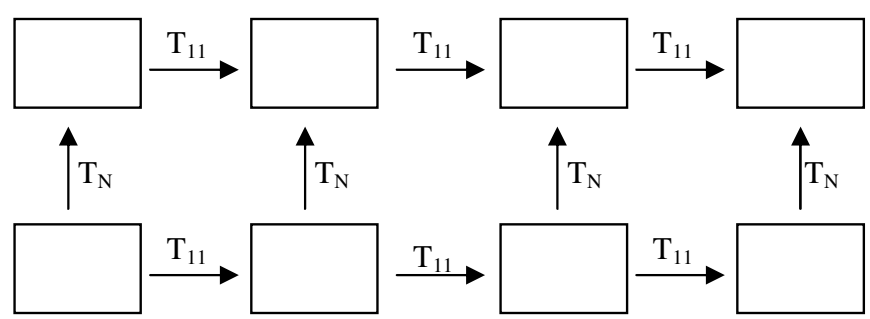

Figure 5: Graphs and networks incorporating $\mathrm{T}_{11}$

of-graphs, $\mathrm{T}_{11}$ occurs among two types of musical object (represented here by small and large nodes), related as different levels of hierarchy. In this particular case, the small-scale and large-scale graphs are identical; both consist of two nodes linked by a $\mathrm{T}_{11}$ arrow. A single process organizes both structural levels. The sequential graph expresses recursion by repeatedly transforming an object by $\mathrm{T}_{11}$. In the product graph, the combination of two smaller sub-networks in each of the vertical and horizontal dimensions suggests a repetition and convergence of two distinct processes on a single set of musical objects.

The simple musical example given in figure 6 a can be analyzed with all three types of structure. With reference to a network-of-networks, it can be interpreted as three chromatic lines related successively from lowest to highest by $\mathrm{T}_{5}$ (see fig. 6b), or as four SC 027 trichords (that is, chords that comprise a pair of five-semitone intervals stacked on top of one another) where each successive trichord is generated by $\mathrm{T}_{11}$ (see fig. 6c). In these two networks-of-networks, there is only one path between successive pitch classes $\left(T_{11}\right.$ in $6 \mathrm{~b}$ and $T_{5}$ in $\left.6 \mathrm{c}\right)$; 
a) A short musical passage

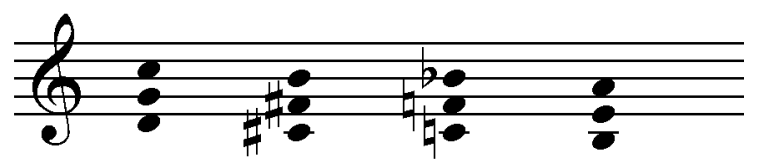

b) A networks-of-networks grouping the semitone lines
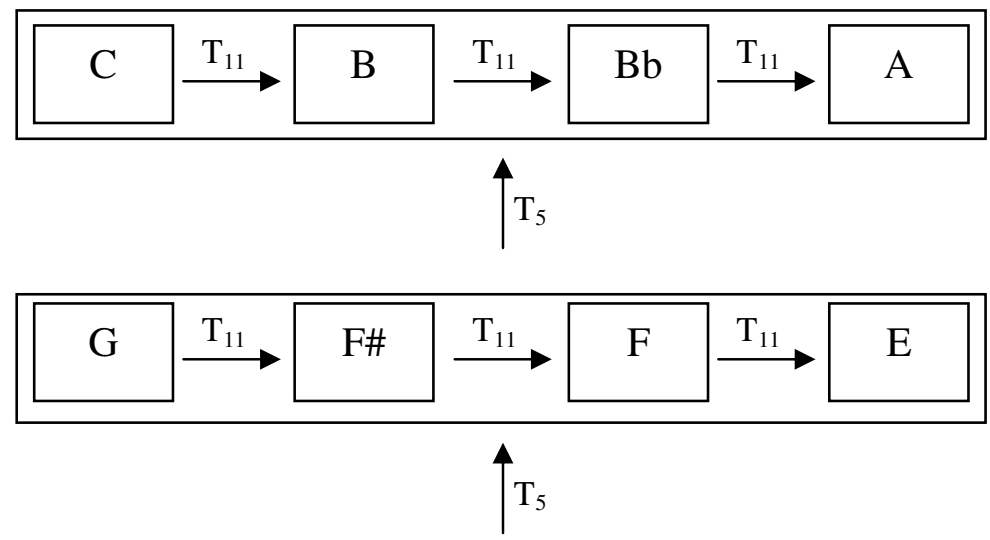
$\mathrm{D}$
$\stackrel{\mathrm{T}_{11}}{\longrightarrow}$

\section{C\#}

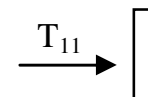
$\mathrm{C}$

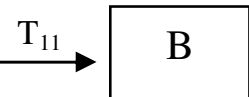

c) A network-of-networks grouping the 027 trichords

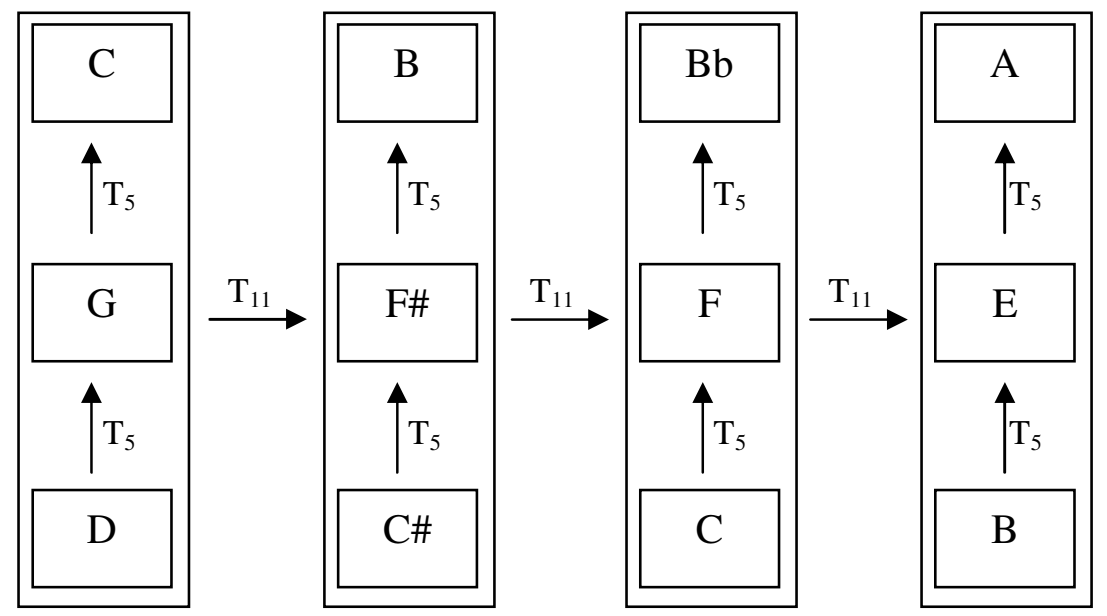

Figure 6: An example involving linear $\mathrm{T}_{11}$ transformations and simultaneous $\mathrm{T}_{5}$ transformations 
d) A product network that does not explicitly specify groupings

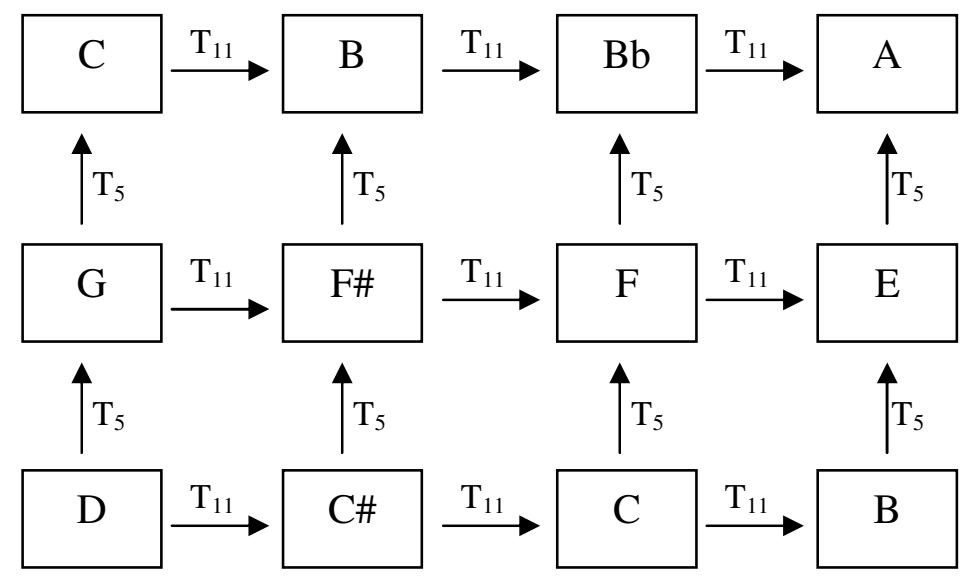

Figure 6 (continued)

there are other paths, but they move from one entire network to another $\left(\mathrm{T}_{5}\right.$ in $6 \mathrm{~b}$ and $\mathrm{T}_{11}$ in $6 \mathrm{c}$ ). A product network interpretation (see fig. $6 \mathrm{~d}$ ), on the other hand, combines both perspectives, modelling the passage as a web of objects, most of which are transformed repeatedly by both $\mathrm{T}_{5}$ and $\mathrm{T}_{11}$. Moreover, in this example each instance of the repeated sub-graphs of the product network forms a sequential graph, as do the large-scale graphs for the two networksof-networks. This immediate sequential replication of a transformation at the same structural level creates a certain continuity in the passage.

The pertinence of these various $T_{11}$ networks is evident when we consider the music on page 10 of the score, beginning in the second system (see fig. 7), which recalls several elements heard at the beginning of the quartet. $\mathrm{T}_{11}$ generates the series of chromatically descending dyads and trichords in the cello (outlined with dashed boxes on the score in fig. 7). It also generates the music of the soprano, which repeats a descending semitone on the word Hell (outlined with a solid box in fig. 7), which alternates with a brief octatonic passage. The three pairs of $\mathrm{T}_{5}$-dyads heard at the end of the system (outlined with a dotted box) also subtly suggest the octatonic collection since their pairs form a subset thereof, the set SC 0167.

Through network representations of both the chromatically descending trichords and the $\mathrm{T}_{5}$-dyads, we can identify how the two types of material are similarly structured. Figure 8 analyzes the first of these, the chromatically descending trichords, in two different ways (as was discussed in connection with fig. 6), each of which says something different about the music. Figure 8a is a network-of-networks, identifying the highest-level objects of the passage as SC 016 trichords (generated by $\mathrm{T}_{5}, \mathrm{~T}_{6}$, and $\mathrm{T}_{11}$ transformations among pitch classes). These objects in turn are transformed repetitively by $\mathrm{T}_{11}$, just as the dyads of the voice's opening music were transformed in the music of figure 3 (another 


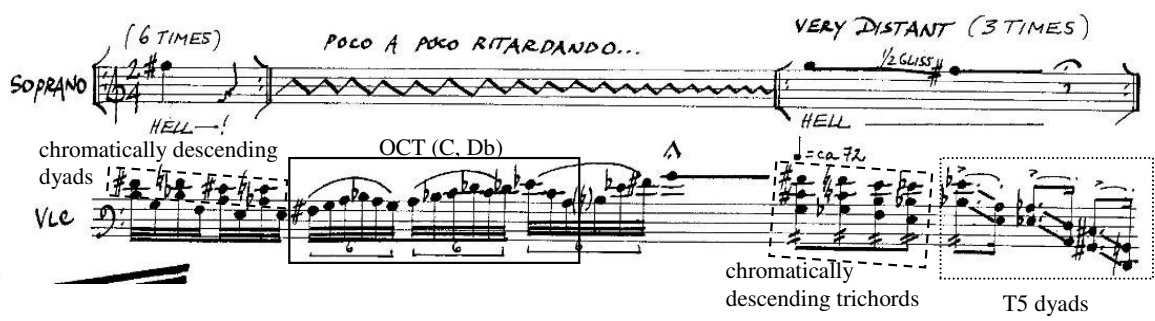

Figure 7: Schafer, Seventh String Quartet, page 10, second system

a)

Interpreted via a network-of-networks:

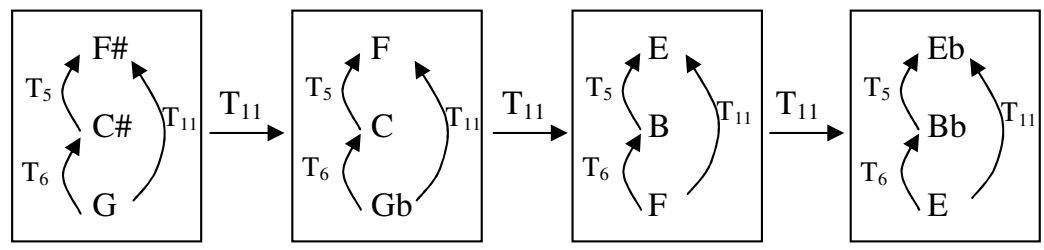

b) Interpreted via a product network:

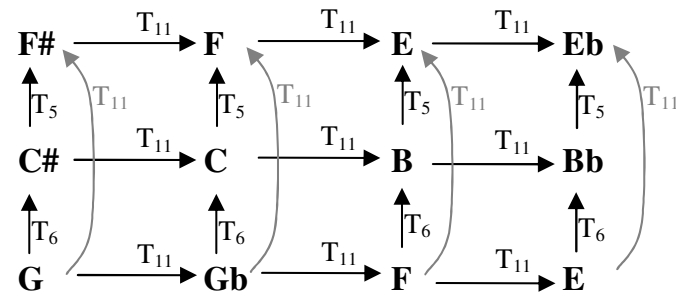

Figure 8: Transformations within the chromatically decending trichords in the cello, page 10, second system, of Schafer's Seventh String Quartet (marked on the previous figure)

reason for considering $\mathrm{T}_{11}$ the characteristic transformation of the movement). In this representation there is no explicit "voice-leading" between registrally corresponding members of the chords: $\mathrm{T}_{11}$ does not occur linearly except implicitly in the mapping of the $\mathrm{F} \#$ node to the $\mathrm{F}$ node as part of the larger-scale $\mathrm{T}_{11}$ transformation.

Figure 8b, a product network, identifies the highest-level objects as pitch classes and projects multiple paths from most of them. It asserts both $\mathrm{T}_{5}+\mathrm{T}_{6}$ $=\mathrm{T}_{11}$ simultaneities (the columns of the network) and three parallel chromatic lines (the rows of the network), suggesting voices that the network-of-networks does not. This polyvalent approach values multiple processes as equal in importance and implies that events in one dimension must coordinate with those in another. For example, the initial low G, the input node of the network, is transformed by $\mathrm{T}_{11}$ both to a simultaneity, $\mathrm{F}^{\sharp}$, and to a successive pitch class, $\mathrm{G}$; w we could interpret the melodic G-to-Gb transformation as an echo of the 
previous G-to-F\# simultaneity. The network (in fig. 8b) also allows multiple paths between the same pairs of objects: for example, the $T_{11}$ transformation from $\mathrm{G}$ to $\mathrm{Gb}$ is one possible path between these pitch classes, but the path $\mathrm{T}_{6}+$ $\mathrm{T}_{11}+\mathrm{T}_{6}$ (through the nodes $\mathrm{G}, \mathrm{C} \#, \mathrm{C}, \mathrm{G}$ ) ) is also possible. Analytically, we might prefer this longer path if we want to observe that these transformations are prominent (for instance, $\mathrm{T}_{11}$ is heard in the soprano in the preceding octatonic motive and the chromatically descending dyads, and $\mathrm{T}_{6}$ is heard melodically in the subsequent dyad motive).

Networks (a) and (b) in figure 8 make additional assertions about the music. The large-scale transformations of network (a) form a sequential network, emphasizing the $\mathrm{T}_{11}$ sequence within the music. Similar transformations occur between each SC 016 trichord and the pitch classes of the surrounding music: the cello's move at the beginning of the system from $\mathrm{G}$ to $\mathrm{E}$ is echoed by the lowest-pitch class of each SC 016 trichord, and the soprano's move from G to $\mathrm{F} \#$ imitates the move from the first to the second trichord of network (a). In network (b), the structure of the product network suggests for certain objects roles that also associate them with the surrounding music. For example, the input node of the network, G (on the lower left), duplicates the extended pitch class that concluded the preceding cello passage. Similarly, the output node, Eb (at the top right of the network), is generated from $\mathrm{B} b$ by a $\mathrm{T}_{5}$ transformation that is immediately repeated in the cello, suggesting a link between the end of this complex and the beginning of the next motivic group. Networks (a) and (b) are not mutually exclusive; indeed, they are closely related since they are constructed from the same two sub-graphs, given in figure 9. Specifically, within the network-of-networks (see fig. 8a) the large-scale network has the same graph as figure $9 \mathrm{a}$, and the small-scale networks that occur within these large-scale nodes replicate figure $9 b$.

Notwithstanding their common formal origins, the two distinctive combinations of sub-graphs represented by figures $8 \mathrm{a}$ and $8 \mathrm{~b}$ isolate different features within the music. Take, for example, the cello's $\mathrm{T}_{5}$ dyad simultaneities at the end of the excerpt. These can be interpreted as a product network that recombines the transformations of the previous passage, $\mathrm{T}_{11}, \mathrm{~T}_{5}$, and $\mathrm{T}_{6}$-an analysis given in figure 10. Unlike the previous analyses, this product network is constructed from three different sub-graphs: two-node $\mathrm{T}_{5}$ and $\mathrm{T}_{6}$ sub-graphs, which incorporate the vertically and horizontally aligned nodes respectively; and a three-node $\mathrm{T}_{11}$ sub-graph, which incorporates the "diagonal" transformations of figure 10. The input node is $\mathrm{B} b$, which immediately generates $\mathrm{E} b$ via the $T_{5}$ transformation heard at the end of the previous passage. The output node is $\mathrm{G}$, the same pitch class given as the input node of figure $8 \mathrm{~b}$. This return suggests a governing role for $\mathrm{G}$, supported by the larger-scale continuity of this pitch class through the $\{B b, E b\}$ dyad and back again.

The layout of figure 10 highlights certain interesting processes in the music. Arrows along the top plane of network (b) correspond to motion in the upper voice, as arrows in the bottom plane do with motion in the lower voice, and the dyad simultaneities are indicated vertically as $\mathrm{T}_{5}$ dyad sub-networks, corresponding to their orientation in the printed music. $\mathrm{T}_{11}$ is heard between 
a) Graph $R$, the 'row graph'

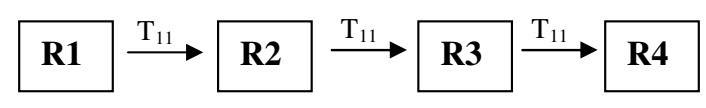

Figure 9: $\quad$ Sub-graphs of figure 8 b) Graph C, the 'column graph'

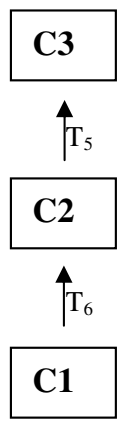

consecutive dyad pairs, represented by the solid-line path, but also occurs between non-consecutive dyads. For example, the path from $\{\mathrm{Bb}, \mathrm{Eb}\}$ to $\{\mathrm{A}, \mathrm{D}\}$ may be understood as either a single transformation of $\mathrm{T}_{11}$-represented by the dotted-line path-or as the combination $\left(\mathrm{T}_{6}+\mathrm{T}_{11}+\mathrm{T}_{6}\right)$ manifested by the solid-line path, heard among consecutive pitch class pairs. The input and output nodes occur at the beginning and end, respectively, of the solid-line path, corresponding to their temporal location within the motive.

The musical material of page 20, third and fourth systems (see fig. 11), presents a kind of climax by developing the recursive possibilities of $\mathrm{T}_{11}$ and its inverse, $\mathrm{T}_{1} . \mathrm{T}_{1}$ occurs as the interval of imitation between the viola and violins, but is also heard (along with $\mathrm{T}_{11}$ ) to dominate local details, as shown in figure 12. $\mathrm{T}_{11}$ sequences (indicated by the repetition of $\mathrm{T}_{11}$ arrows in fig. 12) group short pitch-class motives into segments, which are labelled alphabetically on the figure). The octatonic collections heard in the first system of the passage (compare the collections in boxes a and $\mathrm{b}$ ) progress by $\mathrm{T}_{1}$ and $\mathrm{T}_{11}{ }^{6}$

$\mathrm{T}_{1}$ and $\mathrm{T}_{11}$ transformations also structure motives within a given segment. Consider, for example, the segment in box a of figure 12, which presents fragments of changing octatonic collections. When looked at as a chromatic scale, the passage features a mix of half- and whole-step transformations. But if we see it terms of eight-member octatonic scales, the passage appears rife with identical collections undergoing scale-step transformations. Figure 13 demonstrates this transformationally. The figure uses the notation ${ }_{8} \mathrm{~T}_{1}^{-1}$ to indicate a transposition down one mode step in an eight-member (octatonic) collection, much as $\mathrm{T}_{1}^{-1}=\mathrm{T}_{11}$ is a transposition down a semitone within a twelve-member (chromatic) collection.7 The network also incorporates other transformations; for example, ${ }^{*} \mathrm{~T}_{10}$ is a contextual (mod12) transposition that transforms a pitch

6 While it is true that any pair of octatonic collections will be in a $\mathrm{T}_{1}$ or $\mathrm{T}_{11}$ relationship, the presence of alternating octatonic collections at this point in the work suggests that this relationship is being deliberately exploited in order to further emphasize these transformations.

7 To clarify, in the notation ${ }_{8} \mathrm{~T}_{1}^{-1}$ the subscript 8 refers to an eight-member collection (i.e., the octatonic scale), $T_{1}$ refers to a transformation of one scale step, and -1 indicates the direction of the scale step (a negative value indicates a descending scale step, while a positive value or no value at all indicates an ascending scale step). 


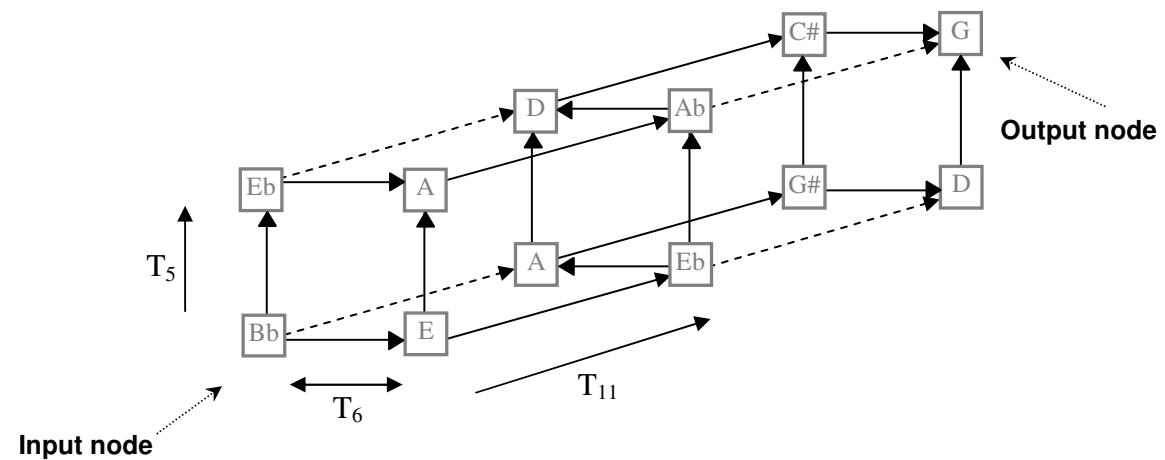

Figure 10: A network indicating transformations among the $\mathrm{T}_{5}$ simultaneity dyads (the last six dyads in the cello) of Schafer's Seventh String Quartet, page 10, second system

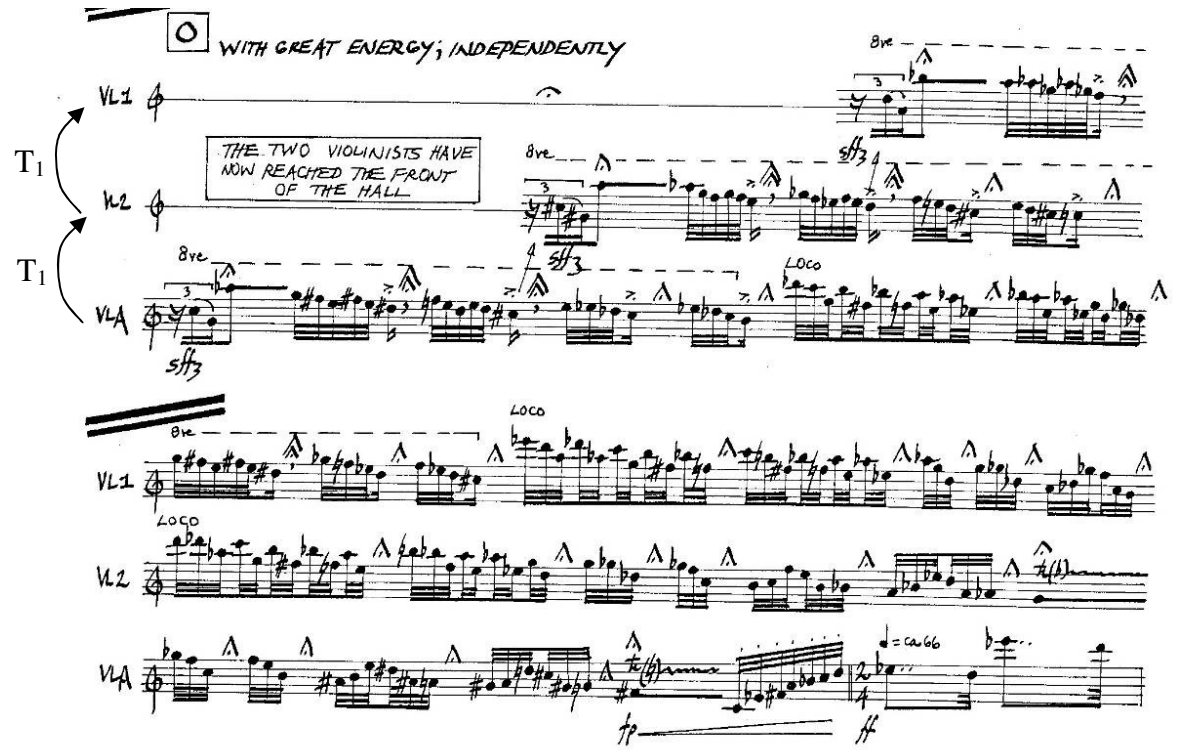

Figure 11: Schafer, Seventh String Quartet, page 20, third and fourth systems (rehearsal O)

class and consequently transposes the octatonic collection associated with it. ${ }^{8}$ This combination of $\bmod 8$ and mod 12 transpositions is not without precedent: Julian Hook, for example, combines mod8 and mod12 transformations in his

$8 \operatorname{Mod}_{12}$ indicates that the transformation occurs within a twelve-member collection, that is, the chromatic collection. The asterisk is used alongside this transformation to indicate that this is not a standard mod12 transposition (even though in some ways it behaves as such), but rather a contextual transposition that modifies elements in addition to the pitch class or pitch-class set. In order to know how this particular transformation affects a pitch class, for example, we must also know to what octatonic collection the pitch class belongs when it appears in the music. This type of transformation is inspired by the "contextual inversions" described by Lewin (1987; 1993) and Lambert (2000); however, the use of contextual transformations in the context I have presented here is, to my knowledge, my own. 


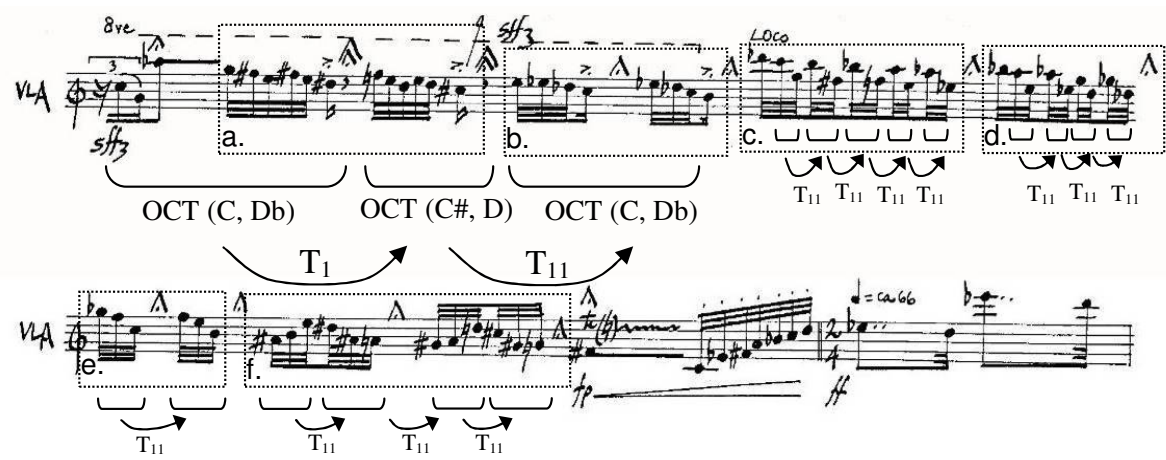

Figure 12: Schafer, Seventh String Quartet, page 20, third and fourth systems, viola only

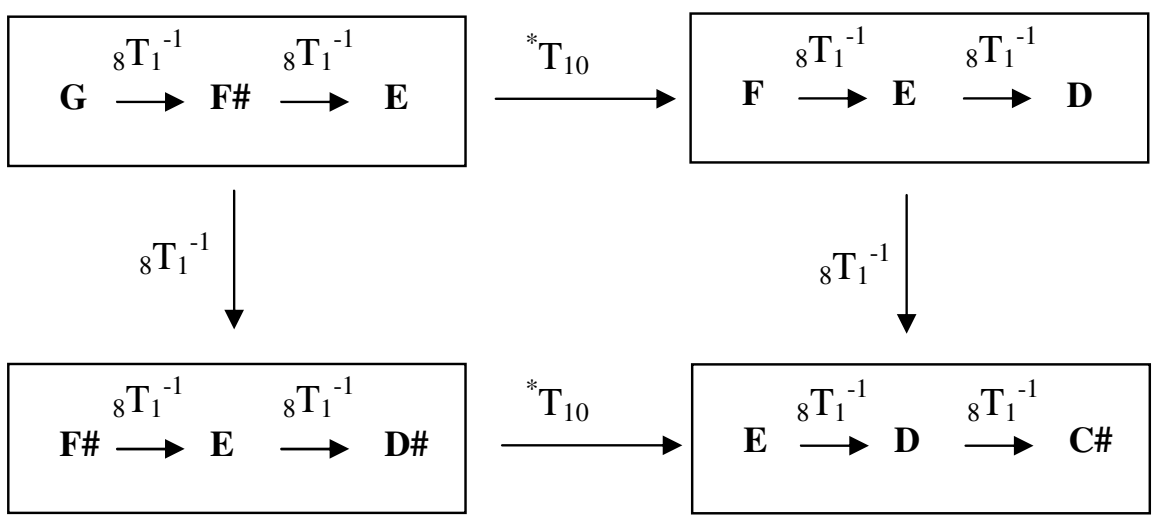

Figure 13: A network analysis of motivic groups within figure 12 (outlined with dotted boxes on the previous figure)

analysis of interscalar transposition within Wagner's Tristan und Isolde (Hook $2007,17)$. However, his analysis focuses on mappings from one collection type to another rather than mappings within a particular collection.

With this set of transformational gestures in hand, we can hear the segment in box a of figure 12 as tightly structured, as depicted transformationally in figure 13. Each trichord is generated via a repeated application of ${ }_{8} \mathrm{~T}_{1}^{-1}$ to its pitch classes. The four trichord networks have identical graphs and generate one another by a combination of ${ }_{8} \mathrm{~T}_{1}^{-1}$ and ${ }^{*} \mathrm{~T}_{10}$ to form a network-of-networks. This particular combination of ${ }^{*} \mathrm{~T}_{10}$ in rows of the network and ${ }_{8} \mathrm{~T}_{1}^{-1}$ in its columns also defines a product network. The replication within the product network suggests the manner in which the entire segment is constructed-by transposing the initial trichord in two different ways (down a mode step to produce the second trichord of the group, and by $\mathrm{T}_{10}$ to produce the second pair of the group). The replication within the network-of-networks, however, suggests an explanation for the choice of transformation; in other words, the transformation that generates the three-note melodic motive determines as well the choice of larger-scale transformation. 
We have seen so far that the $\mathrm{T}_{11}$ gesture is prominent in passages throughout the Quartet; it is employed in the initial motives of the work and returns later, sometimes in material that may not be heard initially as related. A passage in the first system, last measure of page 21 (see fig. 14) gives a good example of how $\mathrm{T}_{11}$ generates objects at multiple levels of the music. In figure 15, three networks-of-networks analyze the music of the violin 1, violin 2, and viola. The structure of the networks reflects the groupings heard in these measures. For example, the first violin's dyad pairs are clearly distinguished by register, and dyad groups are also established in the other two strings by repeated rhythms. The repetition in rhythm and contour from the first to the second half of this measure also suggests a four-note grouping in the first violin. In the first violin network, $\mathrm{T}_{11}$ occurs at three structural levels (between pitch classes, dyads, and tetrachords), whereas in the second violin and the viola it occurs at two structural levels (between pitch classes and between dyads). The smallest-scale dyad networks, the dyad-to-dyad network of the violin 1, and the large-scale violin 1 and violin 2 networks are all isographic, replicating the same two-node graph, which is also a subset of the viola's large-scale network. These similarities observed at different levels suggest that the $\mathrm{T}_{11}$ transformation itself, rather than the objects upon which it acts, is characteristic of the passage.

Replicative networks can depict structural similarities between passages, voices, motives, and other elements, and consequently are a means of illustrating continuity, unity, and motivic development. An analysis of the music of page 24, last system (fig. 16), gives one example of how graphic replication can identify motivic development. In order to capture all the relationships among the voices and their recall of previous material, the network of figure 17 analyzes the boxed notes in the soprano, violin 2, and viola into what is the most elaborate product network yet presented. Below the complete structure are given sub-networks that correspond to each instrumental line.

Each part (voice, violin 2, viola) shares a common "melodic skeleton" from which the rest of the passage is derived, the sequential sub-network $\angle F, E, D \#$, $\mathrm{D}>$, highlighted in bold on the figure. The basic continuity of the passage in this melodic skeleton is created by the three-fold repetition of $\mathrm{T}_{11}$, recalling the three-fold repetitions of $\mathrm{T}_{11}$ depicted in the analyses of figures 7 and 14. The product network aims to represent the "contrapuntal" interrelations of voices in the passage. For example, in the complete structure the vertical arrows are oriented to indicate that the members of the common sub-network $<\mathrm{F}, \mathrm{E}, \mathrm{E}$, $\mathrm{D}>$ are the source for each part. (F was chosen as the "input," or source pitch of the network, since it is the first pitch class of the soprano, the violin 2, and the viola in this passage.) The line $<G b, F, E, D \sharp>$ is replicated enharmonically, as $<F \#, F, E, E b>$ in two parts of the soprano structure, on the syllables con and tal of the soprano's text, respectively. While we might consider indicating the repetition of the initial pitch class by a return to the network's input node F, the shift in register in the music from the first instance of each pitch class to the second disrupts the sense of melodic continuity and repetition that might otherwise be heard. To express this idea another way, the semitone motion between consecutive pitches associates them much more strongly (via register) 


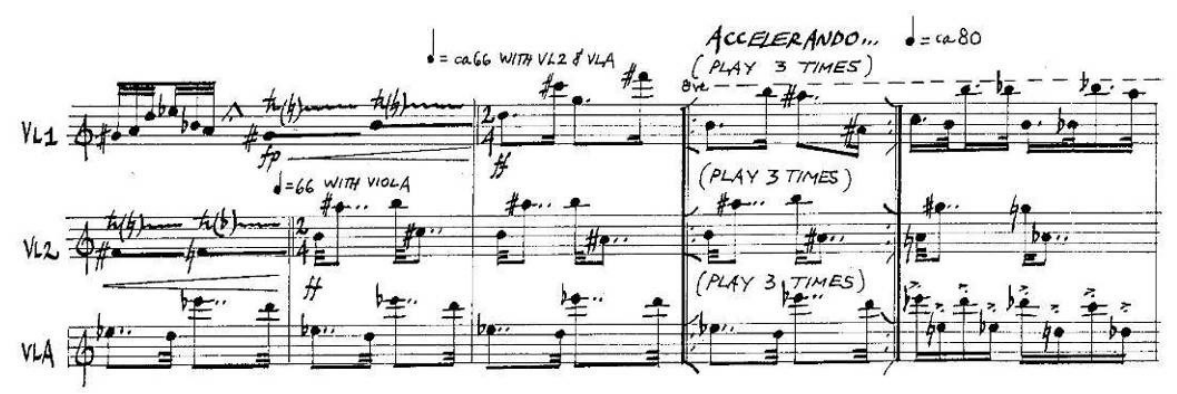

Figure 14: Schafer, Seventh String Quartet, page 21, first and second systems

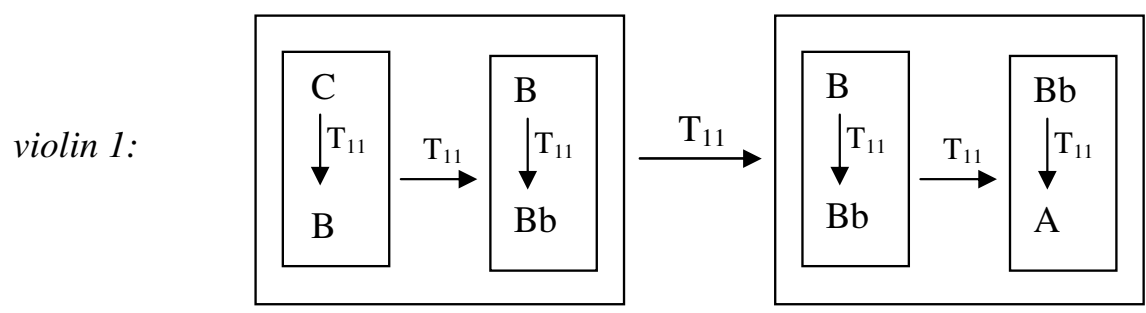

violin 2:

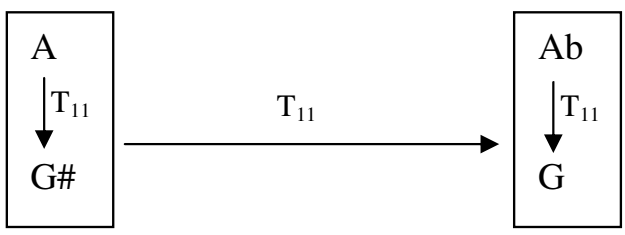

viola:

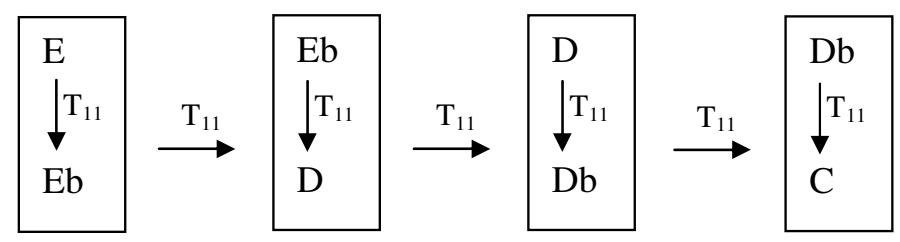

Figure 15: Networks interpreting the pitch classes of the violins and viola on page 21, first system, last measure, of Schafer's Seventh String Quartet

than the non-consecutive octave leap between pitch-class repetitions. While the analyses presented thus far might seem overly abstract because of their seemingly narrow focus on pitch classes and transformations, aspects of the music such as register and rhythm in fact determine how the network is structured and are thus a significant element of the analysis (although this is not always evident at first glance).

Returning to the analysis of figure 17, the product network of the viola shows $\mathrm{F}$ as the input node. From each node in this line, another is generated by $\mathrm{T}_{6}$, shown by diagonal arrows. The resulting nodes $\langle\mathrm{F}, \mathrm{B}\rangle,\langle\mathrm{E}, \mathrm{B} b\rangle,\langle\mathrm{E} b, \mathrm{~A}\rangle$, and 


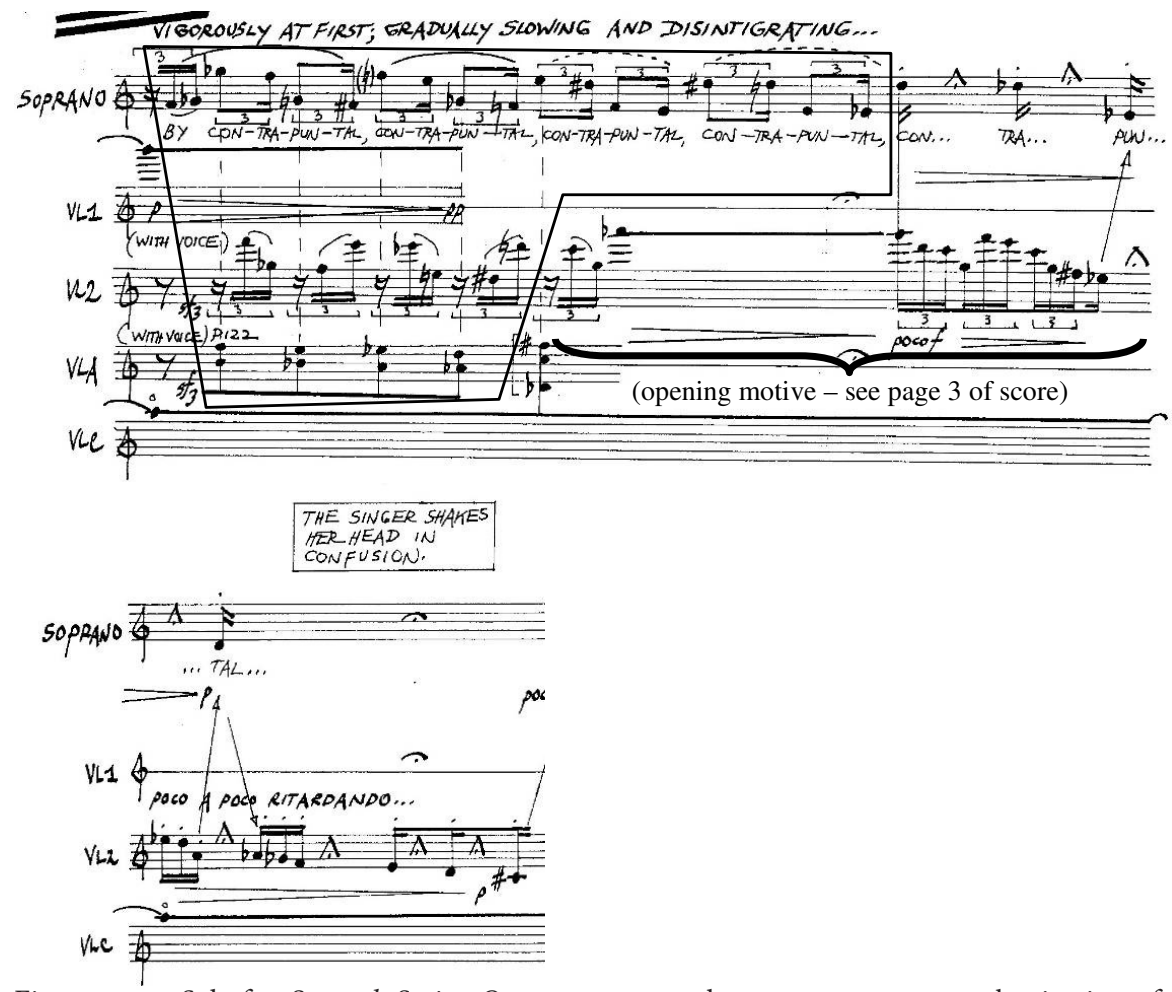

Figure 16: Schafer, Seventh String Quartet, page 24, last system to page 25, beginning of the first system

$<\mathrm{D}, \mathrm{A} b>$ are also connected into a tripartite $\mathrm{T}_{11}$ network; in other words, the two (horizontal) lines have identical sub-graphs. The output node or concluding pitch, $A b$, may be heard to motivate the next events of figure 16 , since it brings back opening motives of the Quartet that strongly emphasize Ab (compare fig. 2, second system and see p. 3 of the score).

Like the music of the viola, that of the second violin's music incorporates two types of sub-network (the melodic skeleton and a two-node $\mathrm{T}_{1}$ network), while the soprano's music in turn combines the melodic skeleton and two separate two-node $\mathrm{T}_{1}$ networks. (The vertical arrows represent the transformation between consecutive beamed pitch classes, while the diagonal ones represent the transformation between the first and second dyads of each slurred grouping). The sub-networks of each instrument lend a certain weight to the nodes of the $<F, E, D \#, D>$ melodic skeleton by showing all the remaining nodes as transformational derivatives. The replicative product network structure of this analysis has several advantages that a network-of-networks does not: it shows the canonic repetition of $<\mathrm{G}$ b, F, E, D\#> (and its enharmonic equivalent) in two parts of the structure (soprano and violin 2), and the whole arrangement has $\mathrm{F}$ as its input and $\mathrm{E}$ as one of two output nodes (the other, $\mathrm{A} b$, was discussed above). The latter replicates the first move, F to E, in the skeleton line. As well, the back face of the figure can be understood as a canonic imitation at $\mathrm{T}_{1}$ of the 
Complete structure:
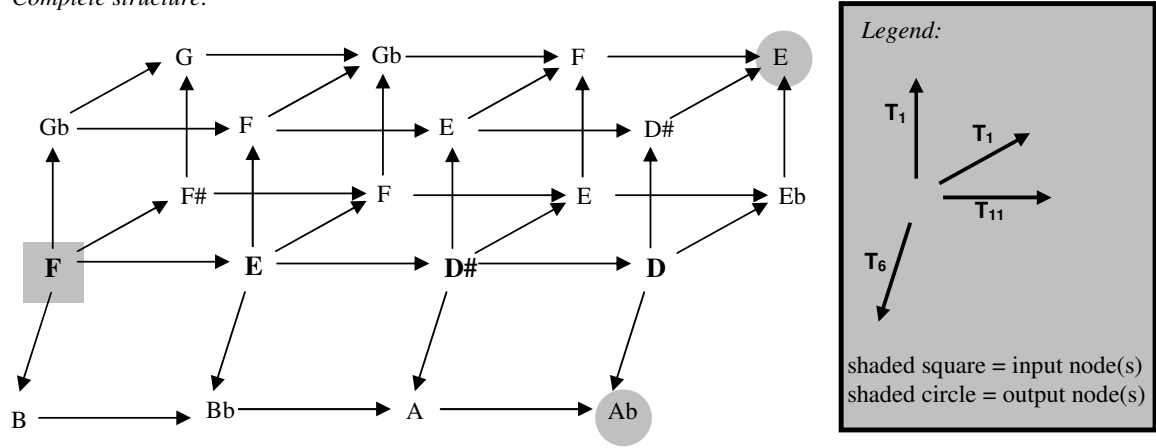

Soprano:

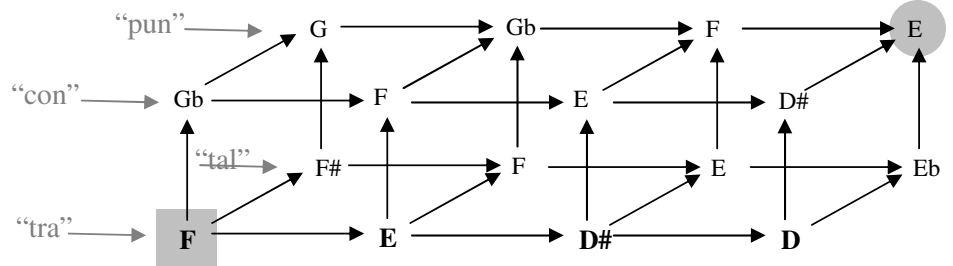

Violin 2:

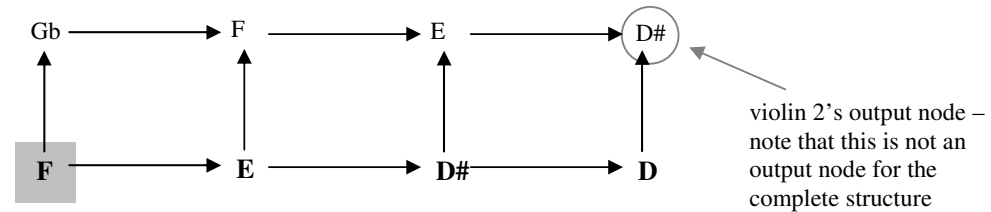

Viola:

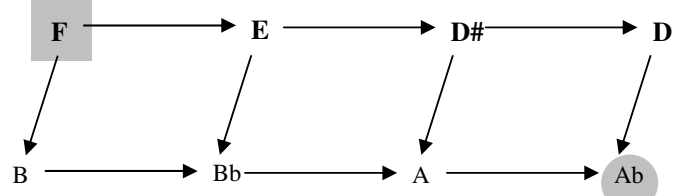

Figure 17: A network incorporating the pitch classes of the soprano, violin 2, and viola during the text "contrapuntal" on pages 24-25 of Schafer's Seventh String Quartet

front face, emphasizing the counterpoint (and thus "painting" the text) of the passage.

The network of figure 17 can show the derivation of subsequent music by means of the same transformations. The extended structure in figure 17 applies $\mathrm{T}_{11}$ twice more to the five right-most nodes of the original network; the original output nodes (E and $A b$ ) are indicated with an empty circle, while the new output nodes (D and $\left.\mathrm{F}^{\sharp}\right)$ are indicated with a shaded circle. These new nodes 


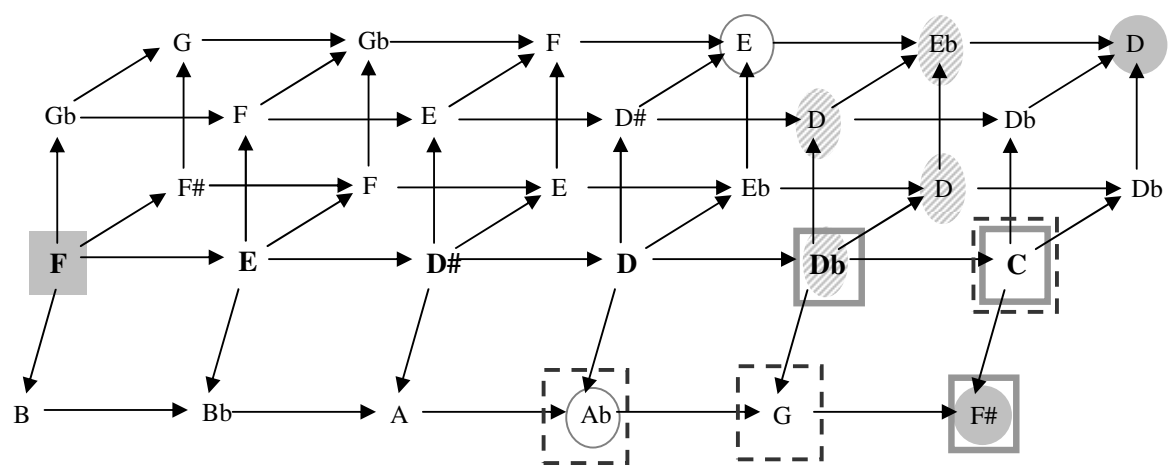

Figure 17 (continued)

incorporate the pitch classes of several motives within the last system of page 24: the shaded ovals identify the nodes associated with the soprano's slowed final iteration of the text contrapuntal (terminating on D). This node appears in previous instances (the syllable con corresponding to the top front $\mathrm{D}$ and tal to the bottom back D). The grey boxes identify members of the viola's last chord within the passage ( $D b, C, F \#)$, and the dashed boxes identify the work's opening motive as it returns in the violin 2 music $(C, G, A b)$. In other words, the reprise of the opening motive and its accompaniment now sound as if they are structured by-products of the $\mathrm{T}_{11}$-recursion. The input to output for the whole network is $\mathrm{F}$ to $\mathrm{D}$, the same as for the melodic skeleton, $<\mathrm{F}, \mathrm{E}, \mathrm{D} \#, \mathrm{D}>9$

Looking back across all the excerpts discussed herein, we see how they share certain elemental structural features, features that are brought out in various ways by network analysis. All the networks introduced here involve scale-step transformation in chromatic or octatonic space. Many also involve the tritone transformation, $\mathrm{T}_{6}$, such as the networks in figures 8,10 , and 17 . The networks all involve the replication of a particular transformational gesture within one or more structural levels: for example, $\mathrm{T}_{11}$ is often replicated among pitch classes at a single structural level, such as in figures $8 \mathrm{~b}, 10$, and 17 , and $\mathrm{T}_{11}$ reappears at multiple structural levels between larger dyads, trichords, and tetrachords, notably in figures 4 and 15 , and in figure 13 as its modular equivalent, ${ }_{8} \mathrm{~T}_{1}^{-1}$. This network saturation establishes the semitone transformation and its variants, rather than the semitone as a pitch-class interval, as the generator of motive in the work. Schafer develops this gesture further by adapting it to octatonic $(\bmod 8)$ passages such as that illustrated in figure 13 .

We have observed the importance of selecting between different kinds of network representations. Such a selection should be determined by the musical features of each excerpt. The analyses herein demonstrate how, for example, the contents of the input and output nodes of a given network highlight the

9 A second output is $F^{\sharp}$, seen in the portion of the network associated with the viola's music. While this output does not reinforce the skeleton line, it does recall the $\left\{\mathrm{F}, \mathrm{G}^{b}\right\}$ pairing that began both the soprano and violin 2 in this excerpt. 
continuities between adjacent passages (as well as certain key passages quite removed in time). The choice of a particular object in a network usually indicates an element considered to be fundamental to the passage, much as the choice of transformational type identifies repeated processes in the music.

In summary, then, the network formats presented here are meant to show gestural objects and their transformations in several contrasting ways. Product networks combine small-scale objects by means of a repeated pattern of transformations, with multiple paths between objects represented at a single structural level. Networks-of-networks, on the other hand, provide information about grouping structure and demonstrate hierarchy through events represented at several musical levels. Both types of network structures can illustrate closure and continuity with the surrounding music. Their effect can also be open ended, for in some cases later analyses may recall and elaborate earlier ones, thus influencing our hearing of the piece retrospectively. The ultimate aim of this paper, then, has been to show how replicative networks are a useful analytical tool for depicting gestural repetition within a work.

\section{ACKNOWLEDGEMENT}

The author wishes to thank R. Murray Schafer for permission to reproduce excerpts of the string quartet.

\section{SELECTEd Bibliography}

Douthett, Jack, and Peter Steinbach. "Parsimonious Graphs: A Study in Parsimony, Contextual Transformations, and Modes of Limited Transposition." Journal of Music Theory 42, no. 2 (1998): 241-263.

Hook, Julian. "Cross-Type Transformations and the Path Consistency Condition." Music Theory Spectrum 29, no. 1 (2007): 1-39.

Kallmann, Helmut, Gilles Potvin, and Kenneth Winters, eds. 1992. The Encyclopedia of Music in Canada, 2nd ed. Toronto: University of Toronto Press.

Klumpenhouwer, Henry. "The Inner and Outer Automorphisms of PitchClass Inversion and Transposition: Some Implications for Analysis with Klumpenhouwer Networks." Intégral 12 (1998): 81-93.

__. "A Generalized Model of Voice-Leading for Atonal Music." PhD diss., Harvard University, 1991.

__. "Network Analysis and Webern's Opus 27/III." Tijdschrift Voor Muziektheorie 3, no. 1 (1998): 24-37.

Lambert, Philip. "On Contextual Transformations." Perspectives of New Music 38 , no. 1 (2000): $45-76$.

_- "Isographies and some Klumpenhouwer Networks They Involve." Music Theory Spectrum 24, no. 2 (2002): 165-195.

Lewin, David. Generalized Musical Intervals and Transformations. New Haven: Yale University, 1987.

- "Klumpenhouwer Networks and Some Isographies That Involve Them." Music Theory Spectrum 12, no. 1 (1990): 83-120. 
1993. Musical Form and Transformation: 4 Analytic Essays. New Haven: Yale University Press, 1993.

. "Transformational Considerations in Schoenberg's Opus 23, Number 3." In Music Theory and Mathematics: Chords, Collections, and Transformations, ed. Jack Douthett, Martha M. Hyde, and Charles J. Smith, 197-221. Rochester: University of Rochester Press, 2008.

__ . "Transformational Techniques in Atonal and Other Music Theories." Perspectives of New Music 21, nos. 1-2 (1982-1983): 312-371.

Molinari Quartet. 2007. “R. Murray Schafer: String Quartets 1-7.” http://www. quatuormolinari.qc.ca/cdsq7a.html.

Morris, Robert. "Voice-Leading Spaces." Music Theory Spectrum 20, no. 2 (1998): 175-208.

Peck, Robert. "Aspects of Recursion in M-Inclusive Networks." Intégral 18-19 (2004-2005): 25-70.

Rahn, John. "Some Remarks on Network Models of Music." In Musical Transformation and Musical Intuition: Eleven Essays in Honor of David Lewin, ed. Raphael Atlas and Michael Cherlin, 225-235. Roxbury, MA: Ovenbird, 1994.

—_ . "The Swerve and the Flow: Music's Relationship to Mathematics." Perspectives of New Music 42, no. 1 (2004): 130-148.

Roeder, John. "Voice Leading as Transformation." In Musical Transformation and Musical Intuition: Essays in Honor of David Lewin, ed. Raphael Atlas and Michael Cherlin, 41-58. Roxbury, MA: Ovenbird, 1994.

Santa, Matthew. "Analysing Post-Tonal Diatonic Music: A Modulo 7 Perspective." Music Analysis 19, no. 2 (2000): 167-201.

___ . "Defining Modular Transformations." Music Theory Spectrum 21, no. 2 (1999): 200-229.

Schafer, R. Murray. Seventh String Quartet. Indian River, ON: Arcana Editions, 1999.

Straus, Joseph N. Introduction to Post-Tonal Theory, 3rd ed. Upper Saddle River, NJ: Pearson/Prentice Hall, 2005.

Tymoczko, Dmitri. "Scale Networks in Debussy." Journal of Music Theory 48, no. 1 (2004): 219-294.

\section{ABSTRACT}

While the text, instrumentation, and performance details of Schafer's Seventh String Quartet (which include an obligato soprano, colour and costume motifs, and texts based on the writings of a schizophrenic woman) seem to distract from the work's pitch structure, seemingly disparate motives can instead be considered closely related because they repeat a particular transpositional gesture. This article uses transformational network analysis, a recently developed theoretical approach incorporating elements of mathematical and musical set theory, to illustrate similarities between these pitch motives. A brief introduction to transformational network analysis is included for those not familiar with its terminology. 


\section{RÉSUMÉ}

Au premier coup d'œil, les éléments du texte, de l'instrumentation, et des conditions d'interprétations semblent nier l'importance de la structure des tons du Quatuor à cordes $n^{\circ} 8$ de Schafer (l'œuvre fait appel à un soprano obligé, des motifs chromatiques et vestimentaires, et des textes basés sur des textes d'une schizophrène). Par contre, on peut déceler des liens étroits entre des motifs musicaux apparemment disparates, qui se conforment à un même geste transpositionnel. Cet article emploie l'analyse de réseaux transformationnels (transformational network analysis), une approche théorique récente qui combine des éléments empruntés aux mathématiques et à la set theory, pour illustrer les similitudes entre ces motifs musicaux. Une introduction brève à l'analyse de réseaux est aussi incluse pour ceux qui ne sont pas familiers avec la terminologie transformationnelle 